\title{
MATHEMATICAL MODELLING OF INDICATIVE PROCESS PARAMETERS OF DUAL-FUEL ENGINES WITH CONVENTIONAL FUEL INJECTION SYSTEM
}

\author{
Sergejus LEBEDEVAS ${ }^{1}$, Saugirdas PUKALSKAS ${ }^{*}$, Vygintas DAUKŠYS ${ }^{3}$ \\ ${ }^{1,3}$ Dept of Marine Engineering, Klaipeda University, Lithuania \\ ${ }^{2}$ Dept of Automobile Engineering, Vilnius Gediminas Technical University, Lithuania
}

Received 21 June 2019; revised 25 August 2019, 22 October 2019; accepted date 21 November 2019

\begin{abstract}
Modern engine research uses multi-dimensional Mathematical Models (MMs) that are applicable to multi-fuel engines. However, their use involves the availability of detailed technical data on the design and characteristics of the engine, which is not always possible. The use of a one-dimensional MM is more expedient for the prediction of engine parameters, but their application for this purpose has not yet been sufficiently investigated. This publication presents the results of numerical studies evaluating the application of a one-dimensional MM with bi-phase Vibe combustion laws for dual-fuel (DF) Diesel (D) and Natural Gas (NG) engine power parameters. The motor test results of a high-speed 4 ČN79.5/95.5 Diesel Engine (DE) with a conventional fuel injection system were used as adequacy criteria. The engines were operated with D100 and DF D20/NG80, in high- (HLM), medium- (MLM), and low- (LLM) load modes, and the angle of Diesel-fuel Injection Timing (DIT) was changed from -1 to $-13^{\circ} \mathrm{CA}$ in the Before Top Dead Center (BTDC) range. Modelling of the single-phase Vibe combustion law has limited applicability for efficient use only in HLM (with an error of 7\%). In the MLM and LLM regimes, owing to non-compliance with real bi-phasic combustion with a strongly extended NG diffusive second phase, the modelling error is 50\%. Individual MM matching in MLM and LLM in a DF D20/ NG80 experiment detected a burn time increase from between 45 and $50{ }^{\circ} \mathrm{CA}$, to 110 and $200{ }^{\circ} \mathrm{CA}$, respectively. Limited use of the one-dimensional MM in the evaluation of DF engine performance has been identified. When comparing a onedimensional MM with experimental data, a bi-phase law of heat release characteristic should be considered for better coincidence. In addition, individual MM matching with an experiment on each engine load mode ensured acceptable accuracy in testing and optimising the parameters of the indicator process, including DIT.
\end{abstract}

Keywords: one-dimensional mathematical model, dual-fuel engine, energy indicators, heat release characteristic, singlephase combustion, bi-phase combustion.

\section{Notations}

Abbreviations:

BTDC - before top dead center $\left[{ }^{\circ} \mathrm{CA}\right]$;

$\mathrm{CA}$ - crank angle;

CC - combustion chamber;

CCR NG - co-combustion ratio of NG [\%];

CFM - combustible forest material;

$\mathrm{D}$ - diesel;

$\mathrm{DE}$ - diesel engine;

DF - dual-fuel;

DIT - D fuel injection timing $\left[{ }^{\circ} \mathrm{CA}\right]$;

HLM - high load mode;

HRF - high reaction fuel;

ICE - internal combustion engine;

MLM - medium load mode;

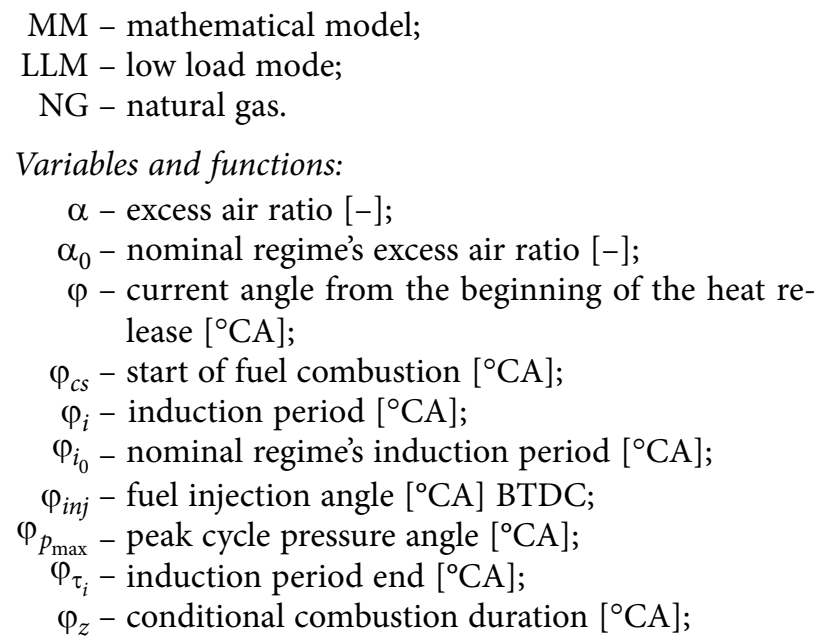

*Corresponding author. E-mail: saugirdas.pukalskas@vgtu.lt 


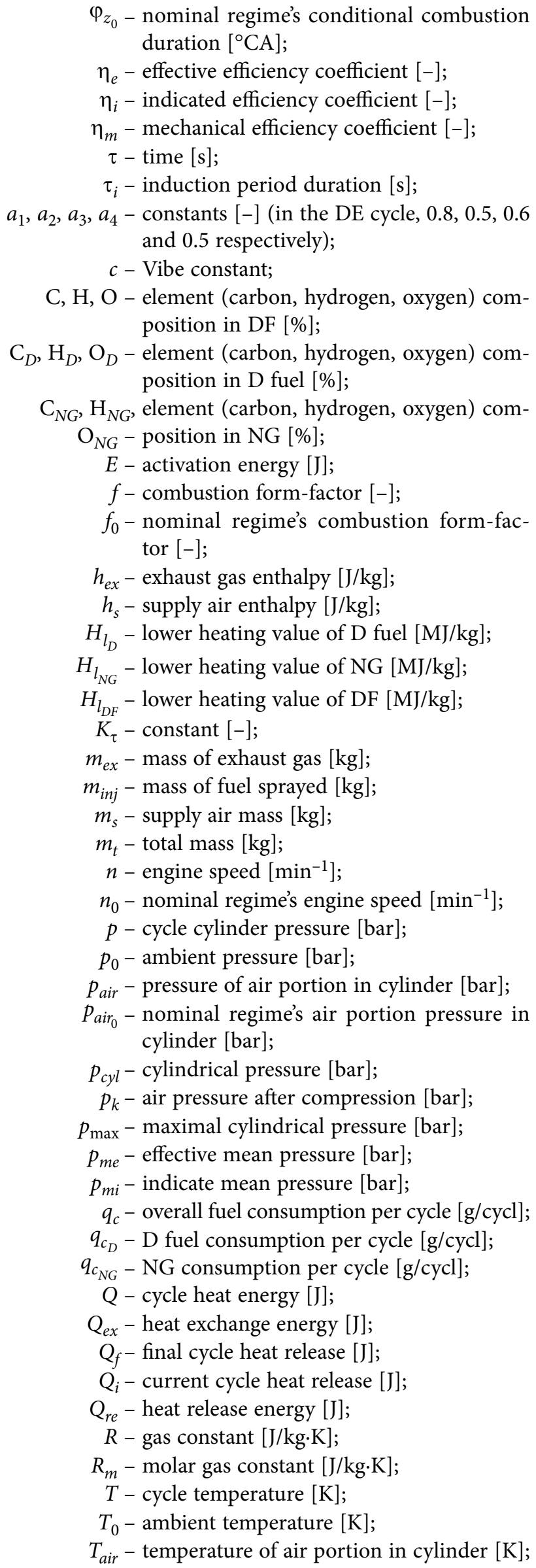

$T_{a i r_{0}}$ - nominal regime's air temperature in cylinder [K];

$T_{k}$ - charged air temperature $[\mathrm{K}]$;

$T_{t}$ - exhaust gas temperature after turbine $[\mathrm{K}]$;

$U$ - internal energy [J];

$V$ - volume of cylinder $\left[\mathrm{m}^{3}\right]$;

$X-$ heat release ratio $[-]$;

$X_{a}$ - abscissa anamorphosis [-];

$Y_{a}$ - ordinate anamorphosis [-].

\section{Introduction}

The use of NG for the conversion of petroleum-derived fossil fuels in $\mathrm{DE}$ is a promising approach for the strategic reduction of harmful emissions and greenhouse gas emissions in transport (IMO 2019a, 2019b; Arteconi et al. 2010; EC 2018). Numerous studies have shown that using NG in a marine DE is one of the most effective means of significantly improving the exploitation and environmental parameters of vehicles: compared to traditional marine fuels, $\mathrm{NO}_{\mathrm{x}}$ emissions are reduced by $85 \ldots 90 \%, \mathrm{CO}_{2}$ - by $10 . . .20 \%, \mathrm{PM}$ and $\mathrm{SO}_{\mathrm{x}}$ are almost non-existent (Anderson et al. 2015; Thomson et al. 2015; HoC 2012; IMO 2016; Carlucci et al. 2009). The scientific aspects are well illustrated by the research results of the Wartsila 20 DF single cylinder marine engine (García Valladolid et al. 2017). In the context of the Tier III level limitation, the authors investigated the principles of rational control of the engine indicator working process necessary to achieve a usually high environmental level without the use of expensive exhaust gas purification technologies. Comprehensive experimental and numerical studies have justified the optimal value of the space and time distribution of a rational pilot portion of liquid fuel injected into the CC as a method of controlling the DF combustion process. As a result, the $\mathrm{NO}_{\mathrm{x}}$ concentration in the exhaust gas is reduced from 3000 to $500 \mathrm{mg} / \mathrm{Nm}^{3}$, which is below the Tier III level in a wide engine operating range ( $\left.p_{m e}=2.1 \ldots 1.3 \mathrm{bar}\right)$. In parallel with extensive experimental studies (García Valladolid et al. 2017; Papagiannakis et al. 2010; Yousefi et al. 2015; Mustafi et al. 2013), at least as much attention is being paid to the development of mathematical modelling technology research (Maurya, Mishra 2017; Abagnale et al. 2014). Multi-dimensional MM are preferred among numerical models. When implemented in software packages, multi-dimensional MMs are effective at solving systems of moment (Navje-Stokes), energy (Furje-Kirghof), and mass-endurance equations - e.g., FIRE (AVL, Austria), KIVA (Laboratory of Energy Research, US), and VECTIS (Ricardo, England). Versatile software platforms such as FLUENT, ANSYS/Flotran, Star CD, and PHOENIX are also commonly used to solve individual numeri$\mathrm{cal}$ and reciprocating type ICE design challenges (Kakaee et al. 2015; Liu et al. 2015; Rapalis et al. 2013). Based on MM benchmarking sources (Kavtaradze 2008), one of the most common is the CFM MM (Heider 1996; Heider et al. 1998), which is applied to cases in which gas is premixed before delivery to the cylinder. In the case of mixed gases 
under high-temperature and pressure conditions, refined equations by Metghalchi and Kech are used (Janbozorgi et al. 2009). In the work by Merker et al. (2006) on DE conversion problems, extended CFM has all the features of the standard CFM model and the modernized CFM upgrade. The model has been expanded mainly for modelling combustion in petrol engines with direct fuel spraying. For example, in FIRE, it is used to implement the SPRAY software application to simulate the fuel injection process. The CFM model, as well as its various modifications, has been well tested to investigate the performance of DF engines. These models have been converted to calculate the combustion process of gaseous fuel in both ICE with spark ignition and DF engines with gas fuel ignition from a pilot portion of $\mathrm{D}$ fuel. To study the formation of toxic components, particularly $\mathrm{NO}_{\mathrm{x}}$, the model developed by Heider (Heider et al. 1998; Liu et al. 2015) is widely used.

One of the main advantages of using multi-dimensional MMs in practice is the wide range of possibilities for thoroughly investigating the physical processes of rapid engine transformation and the formation of harmful components in the engine cylinder. The optimization of these physical processes provides the basis for improving the energy efficiency and ecological parameters of NGpowered engines (García Valladolid et al. 2017; Nithyanandan et al. 2016; Hosmath et al. 2016; Li et al. 2016; Wang et al. 2017). For example, García Valladolid et al. (2017), mathematical modelling techniques in DF engines have been used to investigate the dynamics of the physical interaction between the gaseous and fuel liquid phases the influence of the pilot fuel distribution structure in the cylinder on the NG combustion process. It is reasonable to assume that the angle of the pilot fuel injection rate determines the reaction properties of the combustible mixture, which is evaluated by the distribution coefficient of the air utilization factor, as well as the influence of the CC thermodynamic parameters. In research by Maurya and Mishra (2017), the combustion and ecological characteristics of a 6-cylinder 130/112 engine with a 3D CFD MM DF analysis were investigated using STAR-CD software. The relationships among engine operating parameters, temperature, and harmful component fields in the CC were identified and investigated (García Valladolid et al. 2017). The CFD dynamic model used for this study is implemented in the AVL FIRE-CHEMICIN software. The activity field of the active radical distribution of $\mathrm{OH}$ radicals in the work mixture, at the previous angle of the pilot fuel injection, provides an energy efficiency improvement of $7.5 \%$ and a five- to six-fold reduction in harmful emissions of $\mathrm{C}_{\mathrm{n}} \mathrm{H}_{\mathrm{m}}, \mathrm{CO}$ and $\mathrm{NO}_{\mathrm{x}}$. Therefore, in the initial research phase in addition to the modern practice of multi-dimensional ICE MMs, including conversions to DF engines, well-approved one-dimensional and phenomenological MMs agree with the results of experimental research (Ivanchenko et al. 1983; Lebedev et al. 2003). This result is typical of the preliminary performance of existing DEs fleet models, showing the efficiency of the transfer to NG in the absence of initial data for the effi- cient use of multi-dimensional models. In addition, mathematical modelling of the closed balance of a piston and a turbocharged engine is important for solving technical problems in converting existing engines to $\mathrm{DF}(\mathrm{D} / \mathrm{NG})$ and for evaluating engine performance. In practice, these modelling capabilities in DE research are well characterized by one-dimensional MMs, but their effective use in convertible DEs requires an assessment of their conditions of use, which has not yet been thoroughly studied.

Analogous work has been performed by researchers at Klaipeda University and Vilnius Gediminas Technical University on a high-speed 4ČN79.5/95.5 Diesel Engine (DE) retrofitted to function on a DF D/NG cycle to assess energy efficiency and ecological sustainability. The purpose of the research presented in this publication was to evaluate the efficiency of a one-dimensional MM in the IMPULS software program, to determine the energy and ecological indicators of a conventional fuel injection system during different engine operating modes. The influence of the change in the injection phase of the pilot fuel portion was also assessed. The results of mathematical modelling are compared with experimental engine test result data.

\section{Methodological basics}

For the numerical research transfer function, a one-dimensional MM (Ivanchenko et al. 1983) with a formalised heat transfer law in Vibe was used to calculate the characteristics and energy parameters of the NG DE (Merker et al. 2006).

\subsection{Mathematical model}

The studies used a one-dimensional MM implemented in the IMPULS software (Ivanchenko et al. 1983). The software simulates a closed DE model, both with and without an inflated work process. This is based on quasistatic equations of thermodynamics and gas dynamics, considering the parameters of the exhaust system design, variable gas turbine and compressor efficiency coefficients, heat losses to the engine cooling system, and ambient air parameters. The processes in the engine cylinder are described by a system of differential equations consisting of the laws of energy, the mass and state - Equations (1)-(3):

$$
\begin{aligned}
& \frac{\mathrm{d} U}{\mathrm{~d} \tau}=\frac{\mathrm{d} Q_{r e}}{\mathrm{~d} \tau}-\frac{\mathrm{d} Q_{e x}}{\mathrm{~d} \tau}-p \cdot \frac{\mathrm{d} V}{\mathrm{~d} \tau}+h_{s} \cdot \frac{\mathrm{d} m_{s}}{\mathrm{~d} \tau}-h_{e x} \cdot \frac{\mathrm{d} m_{e x}}{\mathrm{~d} \tau}[\mathrm{kJ} / \mathrm{s}] ; \\
& \frac{\mathrm{d} m_{t}}{\mathrm{~d} \tau}=\frac{\mathrm{d} m_{s}}{\mathrm{~d} \tau}+\frac{\mathrm{d} m_{i n j}}{\mathrm{~d} \tau}-\frac{\mathrm{d} m_{e x}}{\mathrm{~d} \tau}[\mathrm{kg} / \mathrm{s}] ; \\
& \frac{\mathrm{d} p}{\mathrm{~d} \tau}=\frac{m_{t} \cdot R}{V} \cdot \frac{\mathrm{d} T}{\mathrm{~d} \tau}+\frac{m_{t} \cdot T}{V} \cdot \frac{\mathrm{d} R}{\mathrm{~d} \tau}+\frac{R \cdot T}{V} \cdot \frac{\mathrm{d} m_{t}}{\mathrm{~d} \tau}-\frac{p}{V} \cdot \frac{\mathrm{d} V}{\mathrm{~d} \tau}[\mathrm{Pa} / \mathrm{s}]
\end{aligned}
$$

Heat isolation is realized by the Vibe model (Equation (4)) with additions by Woschni Equations (5) and (6), which are widely used to study ICE work process modelling (Merker et al. 2006): 


$$
\begin{aligned}
& X=1-e^{-6.908 \cdot\left(\frac{\varphi}{\varphi_{z}}\right)^{f+1}}[-] ; \\
& f=f_{0} \cdot\left(\frac{\varphi_{i_{0}}}{\varphi_{i}}\right)^{a_{2}} \cdot\left(\frac{p_{a i r_{0}}}{p_{\text {air }}}\right) \cdot\left(\frac{T_{\text {air }}}{T_{\text {air }}}\right) \cdot\left(\frac{n_{0}}{n}\right)^{a_{1}}[-] ; \\
& \varphi_{z}=\varphi_{z_{0}} \cdot\left(\frac{\alpha_{0}}{\alpha}\right)^{a_{3}} \cdot\left(\frac{n_{0}}{n}\right)^{a_{4}}\left[{ }^{\circ} \mathrm{CA}\right] .
\end{aligned}
$$

An important induction cycle induction period for indicator cycle modelling is determined by the compression iterative method - Equations (8)-(10):

$$
\begin{aligned}
& \varphi_{i}=6 \cdot n \cdot \tau_{i}\left[{ }^{\circ} \mathrm{CA}\right] ; \\
& \tau_{i}=K_{\tau} \cdot 10^{-5} \cdot\left(\frac{T}{p}\right)^{0.5} \cdot \exp \left(\frac{E}{R_{m} \cdot T}\right)[\mathrm{s}] ; \\
& \frac{1}{6 \cdot n} \cdot \int_{0}^{\varphi_{\tau_{i}}} \frac{\mathrm{d} \varphi}{\tau_{i}}=1
\end{aligned}
$$

The MM was supplemented and modified to model a DF engine: an additional software block was programmed, which calculates the energy mix of the work mixture (specific heat, enthalpy, internal energy, lower calorific value) according to the actual elemental composition of the DF.

For the calculation of the initial program data, the cyclic portion $q_{c}$ of the dual D-NG fuel with chemical elemental composition $(\mathrm{C}, \mathrm{H}, \mathrm{O})$ is determined as follows.

Fuel consumption per cycle evaluated by Equation (11):

$$
q_{c}=\frac{q_{c_{D}} \cdot H_{l_{D}}+q_{c_{N G}} \cdot H_{l_{N G}}}{H_{l_{D F}}}[\mathrm{~g} / \mathrm{cycl}] .
$$

The lower heat value of the fuel is calculated by the Mendeleev Equation (12):

$$
H_{l_{D F}}=337.5 \cdot \mathrm{C}+1025 \cdot \mathrm{H}-108.3 \cdot \mathrm{O}[\mathrm{MJ} / \mathrm{kg}],
$$

where:

$$
\begin{aligned}
& \mathrm{C}=\mathrm{C}_{D} \cdot(100-\mathrm{CCR} N G)+\mathrm{C}_{N G} \cdot \mathrm{CCR} N G ; \\
& \mathrm{H}=\mathrm{H}_{D} \cdot(100-\mathrm{CCR} N G)+\mathrm{H}_{N G} \cdot \mathrm{CCR} N G ; \\
& \mathrm{O}=\mathrm{O}_{D} \cdot(100-\mathrm{CCR} \mathrm{NG})+\mathrm{O}_{N G} \cdot \mathrm{CCR} \mathrm{NG} .
\end{aligned}
$$

Table 1. Engine specifications

\begin{tabular}{|l|l|}
\hline Model & 4 ČN79.5/95.5 \\
\hline Displacement $\left[\mathrm{cm}^{3}\right]$ & 1896 \\
\hline Bore $\times$ stroke $[\mathrm{mm}]$ & $79.5 \times 95.5$ \\
\hline Maximum power $[\mathrm{kW}] /[\mathrm{rpm}]$ & $66 / 4000$ \\
\hline Maximum torque $[\mathrm{N} \cdot \mathrm{m}] /[\mathrm{rpm}]$ & $180 / 2000 \ldots 2500$ \\
\hline Cooling type & Water cooling \\
\hline Fuel supply system & $\begin{array}{l}\text { Electronic controlled } \\
\text { Bosch VP37 distribution } \\
\text { type fuel pump, one phase } \\
\text { direct injection }\end{array}$ \\
\hline No of cylinders & 4 in line \\
\hline Compression ratio & $19.5: 1$ \\
\hline Aspiration & Turbocharge \\
\hline
\end{tabular}

Co-combustion ratio of natural gas evaluated by Equation (13):

$$
\text { CCR NG }=\frac{q_{c_{N G}} \cdot H_{l_{N G}}}{q_{c_{N G}} \cdot H_{l_{N G}}+q_{c_{D}} \cdot H_{l_{D}}} \cdot 100 \% .
$$

\subsection{Test engine and fuel specification}

The object of the research was a high-speed 4ČN79.5/95.5 DE with a conventional "boot type" fuel injection system (Breitbach 2002; Bosch 2002). The DE main specific parameters are listed in Table 1.

Alignment of the MM with the subject of the study, as well as the evaluation of the modelling results, was performed in comparison with the experimental results car-

\begin{tabular}{|c|c|c|c|}
\hline & \multicolumn{3}{|c|}{ Fuel type } \\
\hline & NG & $\mathrm{D}$ & EN 590:2013+A1:2017 \\
\hline Density $\left[\mathrm{kg} / \mathrm{m}^{3}\right]$ & 0.74 & 832.0 & $820 \ldots 845$ \\
\hline Cetane number & - & 51.3 & $51 \ldots 52.2$ \\
\hline Lower heat value $[\mathrm{MJ} / \mathrm{kg}]$ & 51.7 & 42.8 & - \\
\hline Viscosity $\left[\mathrm{cSt} 40 \mathrm{a}^{\circ} \mathrm{C}\right]$ & - & 2.72 & $2 \ldots 4.5$ \\
\hline $\mathrm{H} / \mathrm{C}$ ratio & - & 1.907 & - \\
\hline Component [\% vol.] & $\begin{array}{l}\text { Methane: } 91.97 \\
\text { Ethane: } 5.75 \\
\text { Propane: } 1.30 \\
\text { Butane: } 0.281 \\
\text { Nitrogen: } 0.562 \\
\text { Carbon dioxide: } 0.0\end{array}$ & $\begin{array}{l}\text { Carbon: } 86.0 \\
\text { Hydrogen: } 13.6 \\
\text { Oxygen: } 0.4\end{array}$ & - \\
\hline
\end{tabular}
ried out on the engine operating on DF. During DF mode engine construction, its system parameters remained unchanged, except for the fuel injection angle $\varphi_{i n j}$, which was changed in the range from -1 to $-13^{\circ} \mathrm{CA}$ BTDC.

The test bench and test equipment are described in detail in the researches by Rimkus et al. (2016, 2017).

Two types of fuel were used during the experiment - D and NG. The D fuel was under the EN 590:2013+A1:2017 standard and the compressed NG was under the ISO 6976:2016 standard (Table 2).

Table 2. Fuel properties 


\subsection{Engine test modes}

Experimental data were used to evaluate MM simulation results on a wide range of engine operating modes (Lebedevas et al. 2019). In each operating mode, characterized by the combination $-p_{m e}, n, \varphi_{i n j}$, the engine parameters were investigated using pure $\mathrm{D}, \mathrm{DF} \mathrm{D} / \mathrm{NG}$ according to the compositions D60/NG40, D40/NG60, and D20/NG80 (where the figures for the D and NG indices correspond to the percentages of D and NG expressed as a percentage of the total fuel energy balance). When the engine is running at $p_{m e}=5.97 \mathrm{bar}$, the mode is called HLM; at $p_{m e}=3.99 \mathrm{bar}$, the mode is called MLM; at $p_{m e}=1.98$ bar, the mode is called LLM. The obtained experimental results showed a consistent deterioration in energy parameters due to an increase in the share of NG in the fuel composition. Therefore, to compare the results of mathematical modelling and experimental studies, only two options were investigated: an engine running on pure $\mathrm{D}$ fuel and on a fuel mixture D20/NG80, i.e. with the maximum proportion of NG used in the studies.

The compatibility of MM with the research object was tested according to the engine's HLM parameters for D. When modelling the engine parameters in partial load modes with DF D-NG, as well as $\varphi_{i n j}$ variations, the parameters of the engine's matching MM were not changed.

The mathematical simulation results were evaluated by comparing them with experimental data obtained by averaging 5 tests at steady state.

\section{Research results and discussion}

In the initial stage of the research, the MM was coordinated with the object under investigation in HLM D $\left(\varphi_{i n j}=-13^{\circ} \mathrm{CA}\right.$ BTDC). The constants used in the MM algorithm, including the Woschni Equations (5), (6) and the turbo aggregate characteristics, were left unchanged while performing engine parameter simulation in partialload MLM and LLM modes; only $\varphi_{i n j}$ was changed in the range from -1 to $-13^{\circ} \mathrm{CA}$ BTDC. The results are compared to the experimental data in Table 3.

One-dimensional MMs, designed primarily for modelling and optimizing the effective energy parameters of an engine $-p_{m e}, T_{t}, p_{\max }, p_{k}, T_{k}$, and are poorly used to modelling real physical processes in a cylinder (Ivanchenko et al. 1983; Merker et al. 2006). The applicability of these MMs to the study of indicative process characteristics is generally limited, mainly due to the actual formalization of combustion and heat exchange processes. The results of the research confirm the good correspondence of the simulation results of the effective parameters and the indicator diagrams (determining $p_{m e}$ ) with the experimental data (Table 3 and Figure 1). For the reasons mentioned above, the current cycle parameters of the indicator process $-T, Q=f(\varphi)$, have increased errors up to $15 \ldots 18 \%$. The error of mathematical modelling of the engine effective energy parameters in HLM and MLM load modes does not exceed $40 \ldots 5 \%$, in LLM mode $7 . . .15 \%$.

Table 3. Comparison of the high-speed 4ČN79.5/95.5 DE parameters functioning in the D fuel experiment and MM parameters $n=2000 \mathrm{~min}^{-1}$

\begin{tabular}{|l|c|c|c|c|c|c|}
\cline { 2 - 7 } \multicolumn{1}{c|}{} & \multicolumn{9}{c|}{ Fuel: $\mathrm{D}$} \\
\cline { 2 - 7 } \multicolumn{1}{c|}{} & \multicolumn{2}{c|}{$p_{m e}=5.97$ bar } & \multicolumn{2}{c|}{$p_{m e}=3.99$ bar } & \multicolumn{2}{c|}{$p_{m e}=1.98$ bar } \\
\hline$\varphi_{\text {inj }}\left[{ }^{\circ} \mathrm{CA}\right]$ BTDC & -1 & -13 & -1 & -13 & -1 & -13 \\
\hline$p_{k}[\mathrm{bar}]$ & $1.52 / 1.53$ & $1.42 / 1.42$ & $1.36 / 1.36$ & $1.267 / 1.27$ & $1.19 / 1.21 / 1.22^{*}$ & $1.17 / 1.17 / 1.17^{*}$ \\
\hline$\alpha[-]$ & $2.87 / 2.58$ & $2.92 / 2.55$ & $3.76 / 3.27$ & $3.59 / 3.14$ & $5.38 / 4.81 / 4.56^{*}$ & $5.22 / 4.62 / 4.36^{*}$ \\
\hline$T_{t}[\mathrm{~K}]$ & $703 / 719$ & $659 / 646$ & $621 / 619$ & $594 / 579$ & $535 / 515 / 525^{*}$ & $524 / 490 / 582^{*}$ \\
\hline$T_{k}[\mathrm{~K}]$ & $338 / 345$ & $333 / 332$ & $326 / 326$ & $323 / 322$ & $316 / 310$ & $319 / 318 / 318^{*}$ \\
\hline$p_{0}[\mathrm{bar}]$ & 1.0 & 1.0 & 1.0 & 1.0 & 1.0 & 1.0 \\
\hline$T_{0}[\mathrm{~K}]$ & 278 & 277 & 275 & 281 & 278 & 281 \\
\hline$q_{c}[\mathrm{~g} / \mathrm{cycl}]$ & 0.01949 & 0.01826 & 0.01407 & 0.01364 & $0.00897 / 0.0095^{*}$ & $0.00876 / 0.0093^{*}$ \\
\hline$p_{\max }[\mathrm{bar}]$ & $69.4 / 66.4$ & $105.8 / 105.4$ & $59.1 / 57.4$ & $92.0 / 94.0$ & $52.2 / 50.0 / 52^{*}$ & $80.3 / 83.6 / 83.7^{*}$ \\
\hline$\varphi_{c s}\left[{ }^{\circ} \mathrm{CA}\right]$ & $8 / 8.6$ & $-6 /-6$ & $7 / 7$ & $-5 /-5$ & $11 / 9 / 9^{*}$ & $-4 /-4 /-4^{*}$ \\
\hline$\varphi_{p_{\max }\left[{ }^{\circ} \mathrm{CA}\right]}$ & $11 / 10$ & $5 / 6$ & $10 / 9$ & $5 / 5$ & $13 / 12 / 12^{*}$ & $2 / 2 / 2^{*}$ \\
\hline$p_{m e}[\mathrm{bar}]$ & $5.96 / 5.67$ & $5.96 / 5.80$ & $3.98 / 3.85$ & $3.98 / 3.85$ & $1.99 / 1.75 / 1.98^{*}$ & $1.99 / 1.70 / 1.95^{*}$ \\
\hline$p_{m i}[\mathrm{bar}]$ & $8.20 / 7.80$ & $8.20 / 7.95$ & $6.24 / 6.00$ & $6.24 / 6.00$ & $4.42 / 3.90 / 4.15^{*}$ & $4.42 / 3.86 / 4.1^{*}$ \\
\hline$\eta_{m}[-]$ & $0.73 / 0.73$ & $0.73 / 0.73$ & $0.635 / 0.64$ & $0.635 / 0.64$ & $0.45 / 0.45 / 0.45^{*}$ & $0.45 / 0.44 / 0.45^{*}$ \\
\hline$\eta_{e}[-]$ & $0.339 / 0.330$ & $0.362 / 0.352$ & $0.313 / 0.304$ & $0.323 / 0.313$ & $0.245 / 0.216 / 0.23^{*}$ & $0.251 / 0.215 / 0.23^{*}$ \\
\hline$\eta_{i}[-]$ & $0.477 / 0.456$ & $0.509 / 0.483$ & $0.493 / 0.472$ & $0.492 / 0.488$ & $0.545 / 0.482 / 0.425^{*}$ & $0.559 / 0.488 / 0.49^{*}$ \\
\hline
\end{tabular}

Notes:

- in the experiment and MM results, $q_{c}$ was increased by $5 \%$ to approximate the cylinder load unevenness;

- in table, for example, values $1.19 / 1.21 / 1.22^{\star}$ means, first value is from experiment, second is from MM and third is MM with $q_{c}$ increased by $5 \%$. 
a)
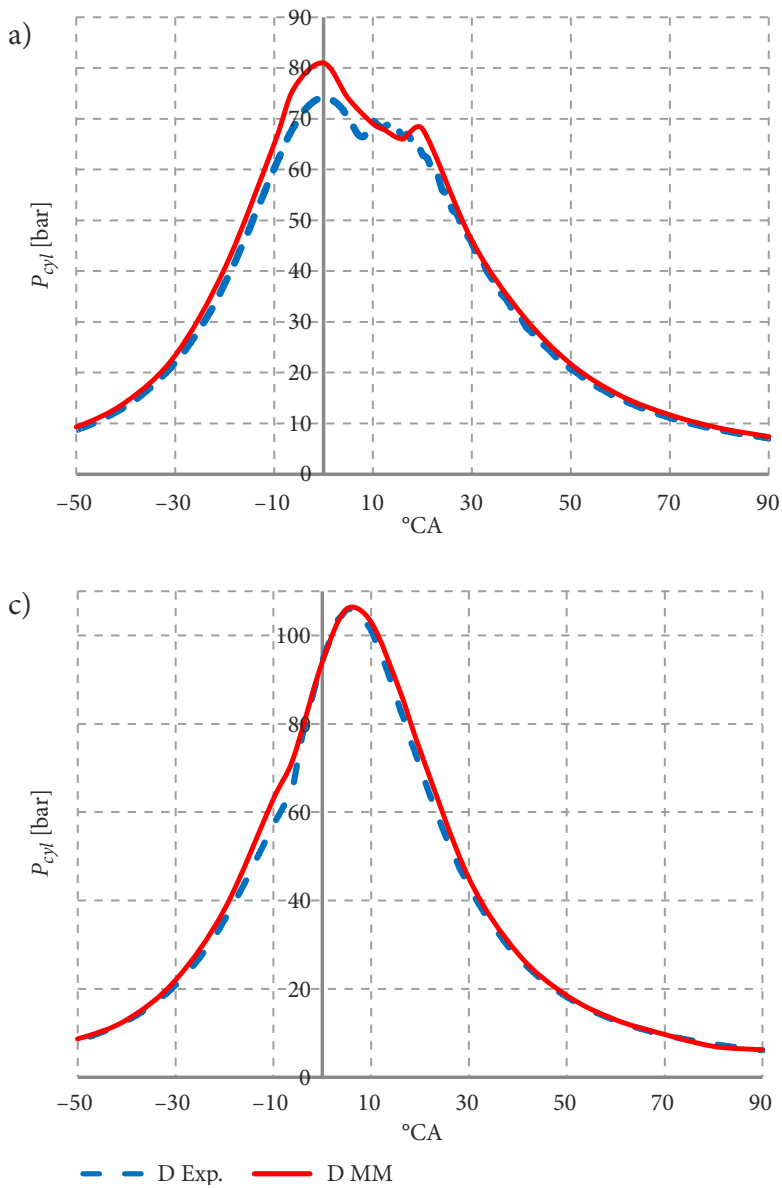

b)

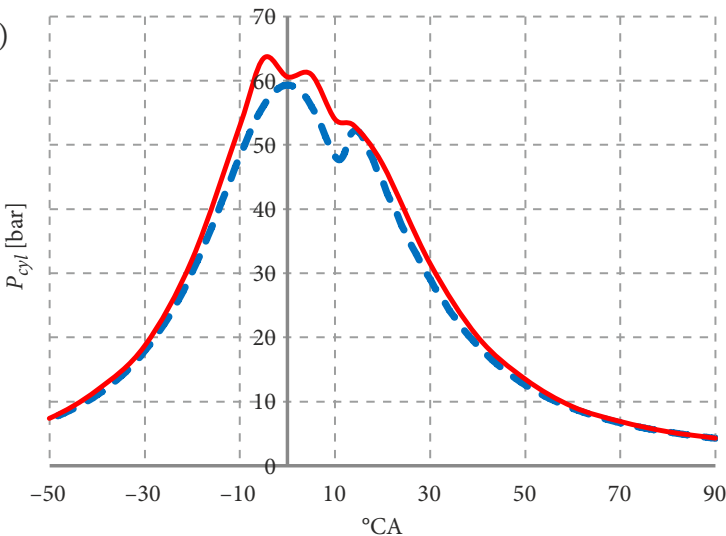

d)

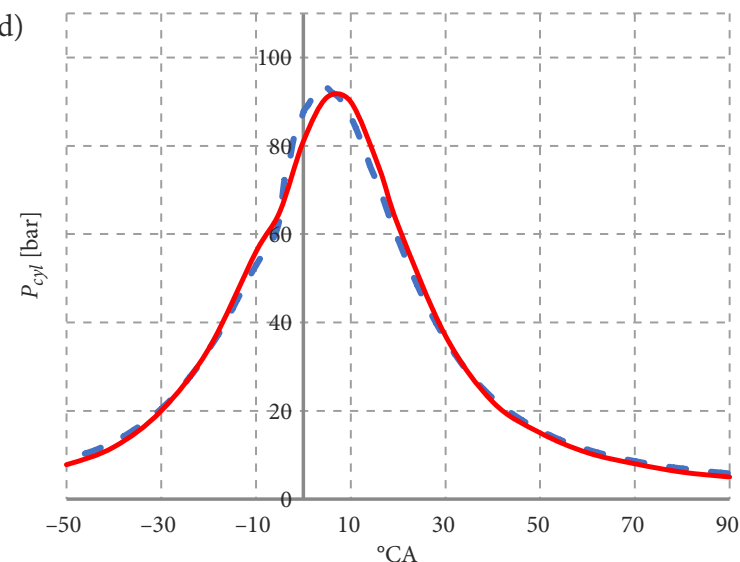

Figure 1. Comparison of the experiment and mathematical modelling indicator diagram parameters of the 4ČN79.5/95.5 engine functioning on D fuel: a $-\mathrm{D} 100, p_{m e}=5.97 \mathrm{bar}, \varphi_{i n j}=-1^{\circ} \mathrm{CA} \mathrm{BTDC} ; \mathrm{b}-\mathrm{D} 100, p_{m e}=1.98 \mathrm{bar}, \varphi_{i n j}=-1{ }^{\circ} \mathrm{CA}$ BTDC; $\mathrm{c}-\mathrm{D} 100$, $p_{m e}=5.97$ bar, $\varphi_{i n j}=-13^{\circ} \mathrm{CA} \mathrm{BTDC} ; \mathrm{d}-\mathrm{D} 100, p_{m e}=3.99 \mathrm{bar}, \varphi_{i n j}=-13^{\circ} \mathrm{CA} \mathrm{BTDC}$

The MM of the IMPULS software works as follows: $f$ and $\varphi_{z}$ are set to one mode (mainly peak power), and in intermediate load modes they are recalculated according to Woschni's statistically determined analytical dependencies $-\varphi_{i}, p_{0}, T_{0}, \alpha, n$ (Merker et al. 2006). The good correlation between the mathematical modelling results and the experimental engine parameters indicates the arrangement of the MM with the engine running on diesel, once again confirming the functionality of the Woschni model. At the next stage of research, the effectiveness of applying a MM to calculate the change in engine parameters for working on a D20/NG80 fuel mixture $\left(p_{m e}=1.98 \ldots 5.97\right.$ bar $)$ was evaluated. This confirms the appropriateness of using an MM for D-NG engine modelling at HLM, MLM, and LLM load modes at $\varphi_{i n j}=-1 \ldots-13^{\circ} \mathrm{CA}$ BTDC, CCR NG 0.8 (or an engine running on D20/NG80 fuel). The modelling results are presented in Table 4 . The results are positively evaluated by simulation in HLM only. The difference between the experimental and modelling parameters does not exceed 2...6\% (Table 5).

In partial load modes, the MLM and LLM modelling error is up to $50 \%$ (Table 6). Notably, the most important discrepancy in the energy parameters $-p_{m e}, p_{m i}, \eta_{e}, \eta_{i}$, is in range of $15 . . .52 \%$.
The large difference in the modelled indicators was obtained under practically uniform conditions of work process execution and modelling: $\varphi_{c s}, p_{k}, T_{k}, \varphi_{i}$ and $q_{c}$. On this basis, it is hypothesised that the deviations of the modelling results for the small regimes of $p_{k}$ in the difference with the experiment are associated with the loss of the gaseous fuel during the purge phase. In HLM $\left(p_{m e}=\right.$ 5.97 bar), the amount of gaseous fuel lost is not high, but its size in LLM $p_{m e}=1.98$ bar is increasing. On the other hand, deviations of $\eta_{e}$ and $\eta_{i}$ are associated with a significant impact on the increase in DF burning time.

The first suspicion has not been confirmed in the assessment of harmful component emission. The conversion of $\mathrm{CH}_{4}$ from the gaseous fuel into the $\mathrm{HC}$ emissions does not exceed $-42 \mathrm{~g} / \mathrm{h}$ in MLM and $-60 \mathrm{~g} / \mathrm{h}$ in LLM (or 1.3 and $2.2 \%$, respectively) of used NG DF D20/NG80. On the other hand, a significant increase in the duration of the heat release characteristic in the functioning of the D20/NG80 was confirmed by the experimental data. For example, $50 \%$ of the heat release in the HLM increases by only $4{ }^{\circ} \mathrm{CA}$, whereas in MLM and LLM, it increased by $12{ }^{\circ} \mathrm{CA}$ and $42^{\circ} \mathrm{CA}$, respectively. The results of the engine indicator process simulation also confirm the observed peculiarity. 
Table 4. Comparison of the experimental and MM parameters of the high-speed 4ČN79.5/95.5 DE in DF D/NG mode, $n=2000 \mathrm{~min}^{-1}$

\begin{tabular}{|c|c|c|c|c|}
\hline \multirow[b]{3}{*}{$\varphi_{i n j}\left[{ }^{\circ} \mathrm{CA}\right] \mathrm{BTDC}$} & \multicolumn{4}{|c|}{ DF: D20/NG80 } \\
\hline & \multicolumn{2}{|c|}{$p_{m e}=5.97 \mathrm{bar}$} & \multirow{2}{*}{$\frac{p_{m e}=3.99 \mathrm{bar}}{-1}$} & \multirow{2}{*}{$\frac{p_{m e}=1.98 \mathrm{bar}}{-1}$} \\
\hline & -1 & -13 & & \\
\hline$p_{k}[\mathrm{bar}]$ & $1.47 / 1.45$ & $1.35 / 1.34$ & $2.38 / 1.36$ & $1.25 / 1.28$ \\
\hline$\alpha[-]$ & $2.30^{\star} / 2.28^{\star \star}$ & $2.54^{\star} / 2.23^{\star \star}$ & $2.57^{\star} / 2.54^{\star \star}$ & $2.93^{\star} / 3.0^{\star *}$ \\
\hline$T_{t}[\mathrm{~K}]$ & $750 / 783$ & $661 / 690$ & $661 / 793$ & $571 / 720$ \\
\hline$p_{k}[$ bar $]$ & $343 / 342$ & $333 / 335$ & $329 / 336$ & $319 / 325$ \\
\hline$q_{c}[\mathrm{~g} / \mathrm{cycl}]$ & $0.01975 /$ & 0.01695 & 0.01746 & 0.01457 \\
\hline$p_{\max }[\mathrm{bar}]$ & $64.2 / 62.8$ & $99.7 / 99.5$ & $57.8 / 74.1$ & $50.1 / 70.5$ \\
\hline$\varphi_{c s}\left[{ }^{\circ} \mathrm{CA}\right]$ & $7 / 7$ & $-5 /-5$ & $8 / 9.5$ & $11 / 11$ \\
\hline$p_{m e}[$ bar $]$ & $5.964 / 6.00$ & $5.964 / 6.08$ & $3.976 / 5.18$ & $1.988 / 4.1$ \\
\hline$p_{m i}[$ bar $]$ & $8.204 / 8.14$ & $8.204 / 8.25$ & $6.242 / 7.32$ & $4.194 / 6.25$ \\
\hline$\eta_{m}[-]$ & $0.727 / 0.73$ & $0.727 / 0.73$ & $0.637 / 0.71$ & $0.474 / 0.65$ \\
\hline$\eta_{e}[-]$ & $0.288 / 0.310$ & $0.366 / 0.348$ & $0.218 / 0.293$ & $0.131 / 0.27$ \\
\hline$\eta_{i}[-]$ & $0.396 / 0.42017$ & $0.462 / 0.473$ & $0.342 / 0.415$ & $0.275 / 0.424$ \\
\hline
\end{tabular}

Note: ${ }^{\star} / *$ - experiment excess air ratio / MM excess air ratio.

Table 5. Comparison of the experimental and MM parameters of the high-speed 4ČN79.5/95.5 DE operating in D20/NG80 HLM $p_{m e}=5.97$ bar, $n=2000 \mathrm{~min}^{-1}$

\begin{tabular}{|l|c|c|c|c|c|c|c|c|}
\cline { 2 - 8 } \multicolumn{1}{c|}{} & $p_{k}[\mathrm{bar}]$ & $\alpha[-]$ & $T_{t}[\mathrm{~K}]$ & $T_{k}[\mathrm{~K}]$ & $p_{m e}[\mathrm{bar}]$ & $p_{m i}[\mathrm{bar}]$ & $\eta_{e}[-]$ & $\eta_{i}[-]$ \\
\hline$\varphi_{\text {inj }}=-13^{\circ} \mathrm{CA}$ BTDC & $1.35 / 1.35$ & $2.54 / 2.67$ & $661 / 686$ & $333 / 324$ & $5.964 / 5.71$ & $8.204 / 7.82$ & $0.366 / 0.333$ & $0.462 / 0.456$ \\
\hline Error [\%] & 0 & +5.1 & +3.6 & -2.8 & -4.5 & -4.9 & -10.0 & -1.3 \\
\hline$\varphi_{\text {inj }}=-1^{\circ} \mathrm{CA}$ BTDC & $1.47 / 1.44$ & $2.30 / 2.41$ & $750 / 808$ & $343 / 342$ & $5.964 / 6.00$ & $8.204 / 8.14$ & $0.288 / 0.310$ & $0.396 / 0.417$ \\
\hline Error [\%] & -2.1 & +4.78 & +7.18 & -0.3 & +0.6 & -0.8 & +7.1 & 5.0 \\
\hline
\end{tabular}

Table 6. Comparison of the experimental and MM parameters of the high-speed 4ČN79.5/95.5 DE operating in D20/NG80 in partial load modes MLM and LLM, $n=2000 \mathrm{~min}^{-1}$

\begin{tabular}{|l|c|c|c|c|c|c|c|c|c|}
\cline { 2 - 10 } \multicolumn{1}{c|}{} & $p_{k}[\mathrm{bar}]$ & $\alpha[-]$ & $T_{t}[\mathrm{~K}]$ & $T_{k}[\mathrm{~K}]$ & $p_{\max }[\mathrm{bar}]$ & $p_{m e}[\mathrm{bar}]$ & $p_{m i}[\mathrm{bar}]$ & $\eta_{e}[-]$ & $\eta_{i}[-]$ \\
\hline$p_{m e}=3.99$ bar & $1.38 / 1.36$ & $2.57 / 2.54$ & $661 / 793$ & $329 / 336$ & $57.8 / 74.1$ & $3.976 / 5.18$ & $6.242 / 7.32$ & $0.218 / 0.293$ & $0.342 / 0.415$ \\
\hline Error [\%] & $-1.5 \%$ & $-1.2 \%$ & +16.6 & +2.1 & +22.0 & +23.0 & +14.7 & +25.6 & +17.6 \\
\hline$p_{m e}=1.98$ bar & $1.25 / 1.28$ & $2.93 / 3.0$ & $571 / 720$ & $319 / 325$ & $50.1 / 70.5$ & $1.988 / 4.1$ & $4.194 / 6.25$ & $0.131 / 0.27$ & $0.275 / 0.424$ \\
\hline Error [\%] & +2.3 & +2.4 & +20.7 & +1.8 & +29.0 & +51.5 & +32.9 & +51.5 & +35.1 \\
\hline
\end{tabular}

Mathematical modelling was accomplished by a variation of the method developed by Bulaty and Glanzmann (1984). For each operation mode, the actual values of $f$ and $\varphi_{z}$ are given in Table 7.

Unlike engine performance with $\mathrm{D}$ fuel, the load drop $\varphi_{z}$ from $65^{\circ} \mathrm{CA}$ in HLM increased to $110{ }^{\circ} \mathrm{CA}$ and $200{ }^{\circ} \mathrm{CA}$ in MLM and LLM, respectively, although the excess air factor $\alpha$ increased from 2.3 to 2.5 and 2.93, respectively. According to Equation (6), $\varphi_{z}$ should instead decrease to $61{ }^{\circ} \mathrm{CA}$ and $56^{\circ} \mathrm{CA}$, respectively. When the engine ran on $\mathrm{D}$ fuel, $\varphi_{z}$ decreased with increasing energy efficiency parameters, especially $\eta_{i}$, as $\alpha$ did in the partialload modes.

An obvious discrepancy between the $\varphi_{z}$ values was obtained based on the experiment and analytical expression - Equation (4). Therefore, the analytical $\varphi_{z}$ determination method for dual engine fuelling must be rationalised.
The physical cause of this fact, as determined by the results of experimental studies (Zhang et al. 2017; Yousefi et al. 2017), reveals peculiarities of the DF combustion process structure and phase change compared to the indicator D process. After the kinetic HRF phase, the next phase of combustion is the combustion of gaseous fuel from the kinetic and diffusive mechanism. The intensity of NG combustion depends on the spread of active radicals in the cylinder. In the absence of sufficient time to prepare for the NG diffusion phase, the insufficient HRF induction period length NG burning process extends with all visible $\eta_{i}$ effects.

Table 8 shows the parameters of the 4 ČN 79.5/95.5 engine when operating on the DF D20/NG80 mode, along with the modelling results, using the corrected $f$ and $\varphi_{z}$ correlation dependence on the parameters $\alpha, p_{k}, T_{k}$ and $n$. 
Table 7. High-speed 4ČN79.5/95.5 DE Vibe heat release law model parameters, $n=2000 \mathrm{~min}^{-1}$

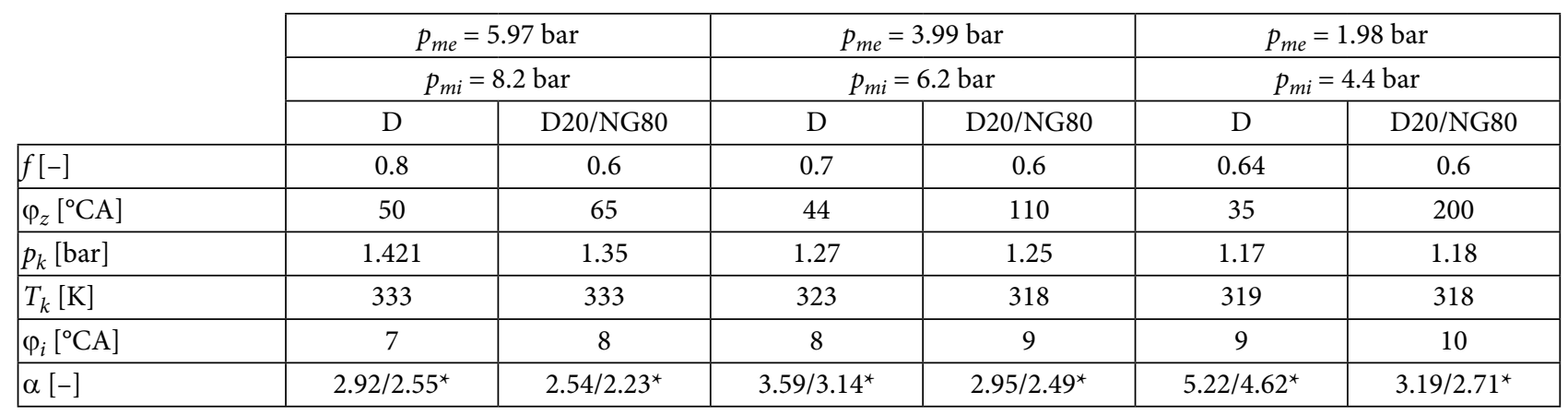

Note: ${ }^{\star}$ - experiment excess air ratio / MM excess air ratio.

Table 8. Mathematical modelling of the high-speed 4ČN79.5/95.5 DE functioning DF D20/NG80 mode indicators using revised $f$ and $\varphi_{z}$ parameters $\left(\varphi_{i n j}=-13^{\circ} \mathrm{CA}\right.$ BTDC)

\begin{tabular}{|l|c|c|c|c|c|c|}
\cline { 2 - 7 } \multicolumn{1}{c|}{} & \multicolumn{2}{c|}{$p_{m e}=5.97$ bar } & \multicolumn{2}{c|}{$p_{m e}=3.99$ bar } & \multicolumn{2}{c|}{$p_{m e}=1.98$ bar } \\
\cline { 2 - 7 } \multicolumn{1}{c|}{} & Exp. & MM & Exp. & MM & Exp. & 0.01255 \\
\hline$q_{c}[\mathrm{~g} / \mathrm{cycl}]$ & 0.0169 & 0.0169 & 0.0143 & 0.0143 & 0.01255 \\
\hline$H_{l_{D F}}[\mathrm{MJ} / \mathrm{kg}]$ & 48.33 & 48.33 & 48.48 & 48.48 & 48.55 & 48.55 \\
\hline$p_{k}[\mathrm{bar}]$ & 1.35 & 1.35 & 1.25 & 1.25 & 1.175 & 1.175 \\
\hline$T_{k}[\mathrm{~K}]$ & 333 & 333 & 318 & 318 & 315 & 315 \\
\hline$p_{\max }[\mathrm{bar}]$ & 100.6 & 100.0 & 79.0 & 76 & 67.3 & 66.3 \\
\hline$\eta_{e}[-]$ & 0.345 & 0.345 & 0.273 & 0.276 & 0.155 & 0.157 \\
\hline$\eta_{i}[-]$ & 0.475 & 0.473 & 0.433 & 0.438 & 0.330 & 0.333 \\
\hline$\eta_{m}[-]$ & 0.726 & 0.730 & 0.630 & 0.630 & 0.470 & 0.470 \\
\hline$p_{m e}[\mathrm{bar}]$ & 5.95 & 5.96 & 3.97 & 4.05 & 1.98 & 2.00 \\
\hline$p_{m i}[\mathrm{bar}]$ & 8.20 & 8.17 & 6.30 & 6.40 & $4.20^{*}$ & 4.28 \\
\hline$\alpha[-]$ & 2.54 & 2.23 & 2.95 & 2.49 & 3.19 & 2.71 \\
\hline
\end{tabular}

With the exception of the exhaust gas temperature $T_{t}$, the energy parameters of the DF engine $\mathrm{MM}\left(p_{\max }, \eta_{i}, \eta_{e}\right.$, $\left.p_{m i}, p_{m e}\right)$ with a sufficient accuracy of $3 . .5 \%$ correspond to the experimental data. The $T_{t}$ mismatch is explained by the simulation of the bi-phase real combustion process in one-dimensional heat release characteristics - Equation (4). Kinetic D and NG combustion phases forming $p_{\text {max }}$, as well as $\eta_{i}$ and $p_{m i}$, are well described by $f$ and $\varphi_{z}$. The further phase of NG diffusion, prolonged combustion, determines the value of $T_{t}$. However, the single-phase heat release model is incomplete, as evidenced by modelling. This indicates that a single-phase Vibe combustion model for DF engines does not correspond to the adequacy of the $T_{t}$ parameter setting and must be modified to a bi-phase combustion model (Maurya, Mishra 2017; Abagnale et al. 2014; Maghbouli et al. 2013). To confirm this (Figure 2), which shows the experimental heat release characteristics of the engine under the D and DF D20/NG80 fuel logarithmic anamorphosis (Merker et al. 2006).

$\mathrm{D}$ fuel performance is accurately approximated by a single linear segment, which means a single-phase form. With DF D20/NG80 fuel, two distinct linear segments with different angular coefficients indicate two stages of the combustion process. One of the measures to improve the energy performance of DF engines is to optimise the DIT.
Experimental studies by García Valladolid et al. (2017), Wang et al. (2017), Zhang et al. (2017) and Yousefi et al. (2017) highlight improvements of dual-engine energy and ecological parameters optimised for DIT - up to $-50{ }^{\circ} \mathrm{CA}$ BTDC. Thus, using a one-dimensional model for changing the DIT is appropriate for an engine functioning on both D and DF. Data on an engine functioning with D fuel are presented in Table 3, and data on DF D20/NG80 fuel with a range of DIT change from -1 to $-13^{\circ} \mathrm{CA}$ BTDC are given in Table 9.

The differences in modelling and experimental data has error from 5 to $7 \%$ in the use of a one-dimensional MM for optimising convertible DF engines with a conventional fuel injection system's DIT optimisation.

Thus, a precondition for the effective use of a onedimensional $\mathrm{MM}$ is its agreement with experimental data for each mode of the simulated load. It is also rational to use a two-phase heat release model instead of a single-phase. The mathematical modelling techniques of one-dimensional models can reasonably be combined with statistical experimental data. Figure 3 (three lines) shows an example of correlative graphical dependencies provided by $\eta_{i}=f\left(\alpha, p_{m e}-\right.$ idem $)$ according to the author's experimental data. Estimating three different load regimes $p_{m e}$ is kept idem. 
a)

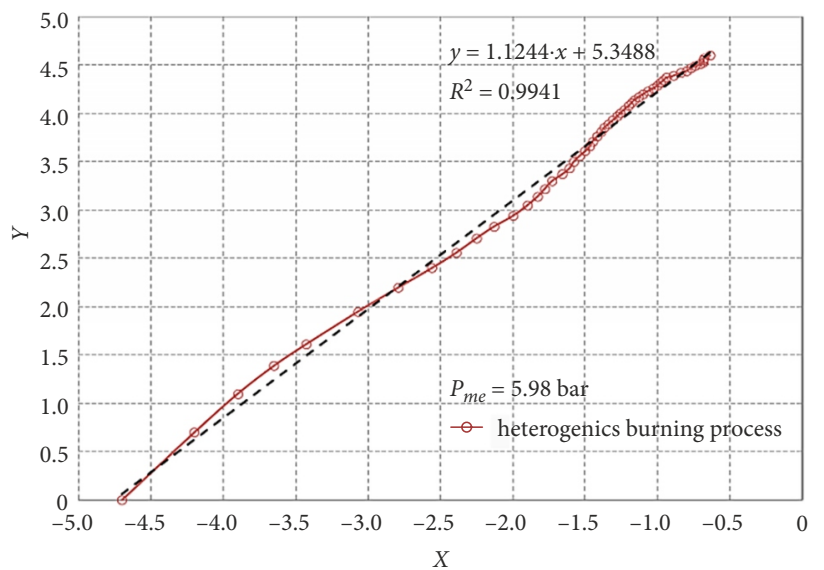

b)

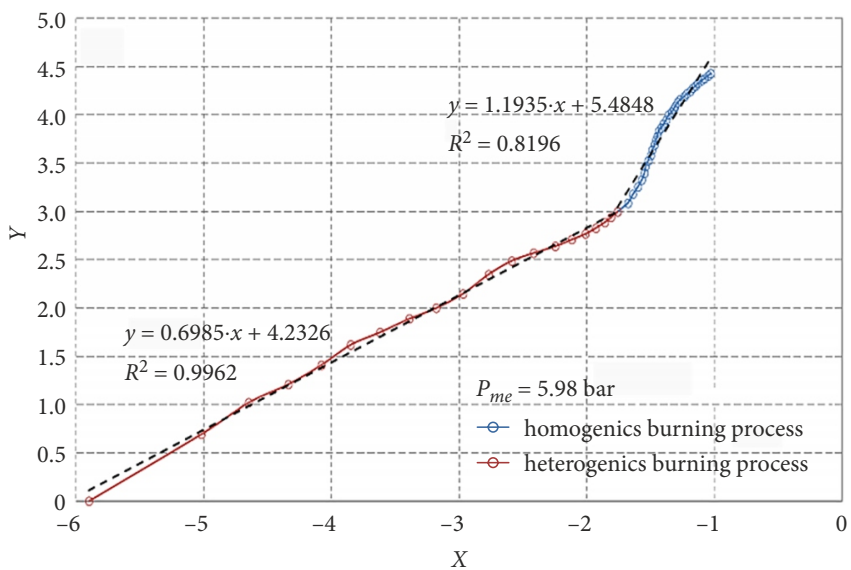

Figure 2. Logarithmic anamorphosis of high-speed 4ČN79.5/95.5 DE functioning with D and DF D20/NG80 fuel heat extraction characteristics: $X_{a}=-\ln \left(\ln \left(1-\frac{Q_{i}}{Q_{f}}\right)+\ln (c)\right), Y_{a}=\left(\frac{1}{f+1}\right) \cdot X+\ln \left(\varphi_{z}\right), c=-6.908: \mathrm{a}-\mathrm{D}$ fuel; b - DF D20/NG80 fuel

Table 9. High-speed 4ČN79.5/95.5 DE functioning on DF D20/NG80 fuel mode with DIT range from -1 to $-13{ }^{\circ} \mathrm{CA}$ BTDC mathematical modelling results

\begin{tabular}{|l|c|c|c|c|c|c|}
\cline { 2 - 7 } \multicolumn{1}{c|}{} & \multicolumn{2}{c|}{$p_{m e}=5.97$ bar } & \multicolumn{2}{c|}{$p_{m e}=3.99$ bar } & \multicolumn{2}{c|}{$p_{m e}=1.98$ bar } \\
\cline { 2 - 7 } \multicolumn{1}{c|}{} & Exp. & MM & Exp. & MM & Exp. & MM \\
\hline$p_{k}$ bar $]$ & 1.47 & 1.45 & 1.38 & 1.37 & 1.25 & 1.26 \\
\hline$\alpha[-]$ & 1.84 & 2.28 & 2.05 & 2.55 & 2.3 & 2.83 \\
\hline$T_{k}[\mathrm{~K}]$ & 343 & 342 & 333 & 336 & 323 & 323 \\
\hline$q_{c}[\mathrm{~g} / \mathrm{cycl}]$ & 0.01975 & 0.01975 & 0.01746 & 0.01746 & 0.01457 & 0.0150 \\
\hline$\varphi_{c s}\left[{ }^{\circ} \mathrm{CA}\right]$ & 7 & 7 & 8 & 9 & 11 & 11 \\
\hline$p_{m e}[\mathrm{bar}]$ & 5.96 & 6.00 & 4.00 & 4.30 & 2.00 & 1.87 \\
\hline$p_{m i}[\mathrm{bar}]$ & 8.20 & 8.12 & 6.24 & 6.6 & 4.20 & 4.00 \\
\hline$\eta_{m}[-]$ & 0.730 & 0.730 & 0.640 & 0.640 & 0.470 & 0.430 \\
\hline$\eta_{e}[-]$ & 0.288 & 0.310 & 0.218 & 0.240 & 0.131 & 0.121 \\
\hline$\eta_{i}[-]$ & 0.396 & 0.417 & 0.342 & 0.370 & 0.275 & 0.257 \\
\hline$p_{\max }[\mathrm{bar}]$ & 64.2 & 62.8 & 57.8 & 55.0 & 50.1 & 48.4 \\
\hline
\end{tabular}

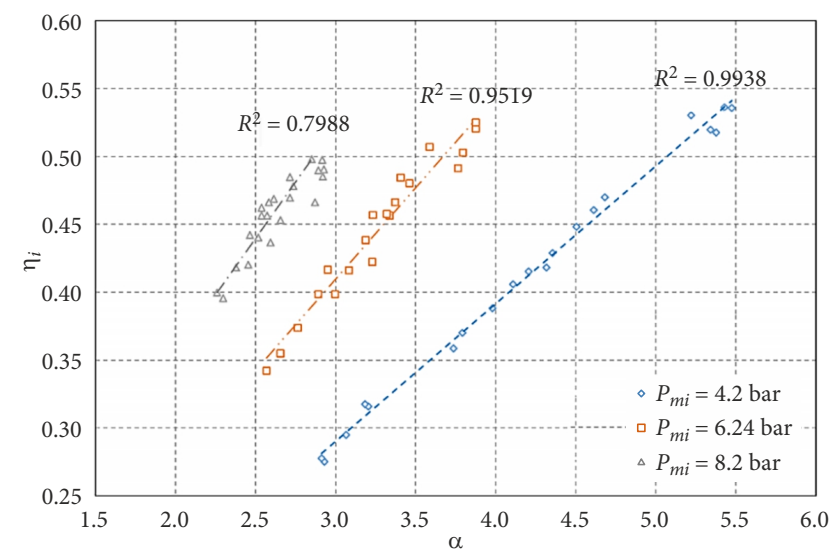

Figure 3. DF engine $\eta_{i}$ and $\alpha$ parameter relation during different loads CCR NG and $\varphi_{i n j}(\mathrm{CCR} N G=0 \ldots 0.8$; $\varphi_{i n j}=-1 \ldots-13^{\circ} \mathrm{CA}$ BTDC)
To determine the energy efficiency indicators $\eta_{i}$ of an engine under both a D load and a DF D/NG load $\left(p_{m e}-\right.$ idem) in a given load mode, it is sufficient to evaluate $\alpha$. The rational DIT phase is chosen to be modelled by customising the MM to each engine load mode with experimental data. The research results show limited possibilities for simulating a one-dimensional MM with formalised heat release characteristics for simulating the DF engine indicator processes. For a deeper understanding of DF engine indicator processes and the heat release mechanism in the engine cylinder, the authors continue the research on that topic by using multi-dimensional mathematical modelling software AVL FIRE. The authors are very thankful to AVL List GmbH for providing the AVL FIRE software. 


\section{Conclusions}

Numerical studies using multi-dimensional MM have become one of the most important components in the development of $\mathrm{DE}$ conversion to $\mathrm{DF}(\mathrm{D} / \mathrm{NG})$ technology. At the same time, in the initial stages of research and in solving technological problems of engine design modification, in parallel with multi-dimensional MM rational onedimensional MM, which implement closed energy balance of piston engine part and air inflator, are applied.

The aim of the research carried out by the authors was to supplement the information lacking in the literature on the possibilities of rational use of a one-dimensional MM for the investigation of the parameters of the DF engine indicated process; the subject of the research was a highspeed 4ČN79.5/95.5 DE with a traditional fuel injection system.

A one-dimensional MM with a formalized single-phase heat release characteristic has limited applications. One of the main reasons for this is the intense lengthening of the fuel combustion process with dual fuel in medium $\left(p_{m e}=\right.$ 3.99 bar) and low ( $p_{m e}=1.98$ bar) load modes: compared to high ( $p_{m e}=5.97$ bar) load modes the difference is 1.7 and 3 times respectively. The use of one-dimensional MM in the mathematical modelling of DF engines is rational for the prediction of the effective energy parameters of the engine $\left(p_{m e}, \eta_{e}, p_{k}, T_{k}\right.$, etc.), since the modelling errors of the indicated process parameters reach up to $15 \%$. It is also necessary to reconcile the one-dimensional $\mathrm{MM}$ with the experimental data for each simulated engine partial load mode.

In the next stage of research, it is planned to evaluate the adequacy of one-dimensional MM functionality by changing the single-phase heat characteristic to bi-phase, in order to expand the utilization of single-zone MM for modelling the parameters of the motor indicated process.

\section{Acknowledgements}

The authors are grateful to AVL Advanced Simulation Technologies for providing the AVL FIRE simulation software.

AVL FIRE was acquired by signing a cooperation agreement between AVL Advanced Simulation Technologies and the Faculty of Marine Technologies and Natural Sciences of Klaipeda University.

\section{References}

Abagnale, C.; Cameretti, M. C.; De Simio, L.; Gambino, M.; Iannaccone, S.; Tuccillo, R. 2014. Numerical simulation and experimental test of dual fuel operated diesel engines, Applied Thermal Engineering 65(1-2): 403-417.

https://doi.org/10.1016/j.applthermaleng.2014.01.040

Anderson, M.; Salo, K.; Fridell, E. 2015. Particle- and gaseous emissions from an LNG powered ship, Environmental Science \& Technology 49(20): 12568-12575.

https://doi.org/10.1021/acs.est.5b02678
Arteconi, A.; Brandoni, C.; Evangelista, D.; Polonara, F. 2010. Life-cycle greenhouse gas analysis of LNG as a heavy vehicle fuel in Europe, Applied Energy 87(6): 2005-2013.

https://doi.org/10.1016/j.apenergy.2009.11.012

Bosch, R. 2002. Dieselmotor-Management. Vieweg+Teubner Verlag, Wiesbaden GmbH. 479 S.

https://doi.org/10.1007/978-3-322-99413-4 (in German).

Breitbach, H. 2002. Fuel Injection Systems Overview. Delphi Corporation, Gillingham, UK.

Bulaty, T.; Glanzmann, W. 1984. Bestimmung der Wiebe-Verbrennungsparameter, MTZ - Motortechnische Zeitschrift 45(7-8): 299-303. (in German).

Carlucci, A. P.; Laforgia, D.; Saracino, R. 2009. Effects of incylinder bulk flow and methane supply strategies on charge stratification, combustion and emissions of a dual-fuel DI diesel engine, SAE Technical Paper 2009-01-0949. https://doi.org/10.4271/2009-01-0949

EC. 2018. Transport in the European Union: Current Trends and Issues. European Commission (EC). 144 p. Available from Internet: https://ec.europa.eu/transport/sites/transport/ files/2018-transport-in-the-eu-current-trends-and-issues.pdf

EN 590:2013+A1:2017. Automotive Fuels. Diesel. Requirements and Test Methods.

García Valladolid, P.; Tunestål, P.; Monsalve-Serrano, J.; García, A.; Hyvönen, J. 2017. Impact of diesel pilot distribution on the ignition process of a dual fuel medium speed marine engine, Energy Conversion and Management 149: 192-205. https:// doi.org/10.1016/j.enconman.2017.07.023

Heider, G. 1996. Rechenmodell zur Vorausrechnung der NO-Emission von Dieselmotoren. Dissertation. Technische Universität München, Deutschland. 144 S. (in German).

Heider, G.; Woschni, G.; Zeilinger, K. 1998. 2-Zonen Rechenmodell zur Vorausrechnung der NO-Emission von Dieselmotoren, MTZ - Motortechnische Zeitschrift 59(11): 770-775. https://doi.org/10.1007/BF03226479 (in German).

HoC. 2012. Sulphur Emissions by Ships. Sixteenth Report of Session 2010-12. Volume II. Additional Written Evidence. House of Commons (HoC), Transport Committee, London, UK. 35 p. Available from Internet: https://publications.parliament.uk/ pa/cm201012/cmselect/cmtran/1561/1561vw.pdf

Hosmath, R. S.; Banapurmath, N. R.; Khandal, S. V.; Gaitonde, V. N.; Basavarajappa, Y. H.; Yaliwal, V. S. 2016. Effect of compression ratio, $\mathrm{CNG}$ flow rate and injection timing on the performance of dual fuel engine operated on honge oil methyl ester (HOME) and compressed natural gas (CNG), Renewable Energy 93: 579-590.

https://doi.org/10.1016/j.renene.2016.03.010

IMO. 2019a. Greenhouse Gas Emissions. International Maritime Organization (IMO). Available from Internet: http://www. imo.org/en/OurWork/Environment/PollutionPrevention/ AirPollution/Pages/GHG-Emissions.aspx

IMO. 2019b. Prevention of Air Pollution from Ships. International Maritime Organization (IMO). Available from Internet: http://www.imo.org/en/OurWork/Environment/PollutionPrevention/AirPollution/Pages/Air-Pollution.aspx

IMO. 2016. Studies on the Feasibility and Use of LNG as a Fuel for Shipping. International Maritime Organization (IMO). 290 p. Available from Internet: http://www.imo.org/en/OurWork/ Environment/PollutionPrevention/AirPollution/Documents/ LNG\%20Study.pdf

ISO 6976:2016. Natural Gas - Calculation of Calorific Values, Density, Relative Density and Wobbe Indices from Composition. 
Ivanchenko, N. N.; Krasovskij, O. G.; Sokolov, S. S. 1983. Vysokij nadduv dizelej. Leningrad: Mashinostroenie. 198 s. (in Russian).

Janbozorgi, M.; Ugarte, S.; Metghalchi, H.; Keck, J. C. 2009. Combustion modeling of mono-carbon fuels using the rate-controlled constrained-equilibrium method, Combustion and Flame 156(10): 1871-1885.

https://doi.org/10.1016/j.combustflame.2009.05.013

Kakaee, A.-H.; Rahnama, P.; Paykani, A. 2015. Influence of fuel composition on combustion and emissions characteristics of natural gas/diesel RCCI engine, Journal of Natural Gas Science and Engineering 25: 58-65.

https://doi.org/10.1016/j.jngse.2015.04.020

Kavtaradze, R. Z. 2008. Teorija porshnevyh dvigatelej: Special'nye glavy. Moskva: MGTU im. N. Je. Baumana. 720 s. (in Russian).

Lebedev, S. V.; Lebedeva, G. V.; Matievskij, D. D.; Reshetov V. I. 2003. Formirovanie konstruktivnogo rjada porshnej dlja tipazha vysokooborotnyh forsirovannyh dizelej. Altajskij gosudarstvennyj tehnicheskij universitet im. I. I. Polzunova, Barnaul, Rossija. 89 s. (in Russian).

Lebedevas, S.; Pukalskas, S.; Daukšys, V.; Rimkus, A.; Melaika, M.; Jonika, L. 2019. Research on fuel efficiency and emissions of converted diesel engine with conventional fuel injection system for operation on natural gas, Energies 12(12): 2413. https://doi.org/10.3390/en12122413

Li, W.; Liu, Z.; Wang, Z. 2016. Experimental and theoretical analysis of the combustion process at low loads of a diesel natural gas dual-fuel engine, Energy 94: 728-741. https://doi.org/10.1016/j.energy.2015.11.052

Liu, J.; Zhang, X.; Wang, T.; Zhang, J.; Wang, H. 2015. Experimental and numerical study of the pollution formation in a diesel/CNG dual fuel engine, Fuel 159: 418-429. https://doi.org/10.1016/j.fuel.2015.07.003

Maghbouli, A.; Saray, R. K.; Shafee, S.; Ghafouri, J. 2013. Numerical study of combustion and emission characteristics of dual-fuel engines using 3D-CFD models coupled with chemical kinetics, Fuel 106: 98-105. https://doi.org/10.1016/j.fuel.2012.10.055

Maurya, R. K.; Mishra, P. 2017. Parametric investigation on combustion and emissions characteristics of a dual fuel (natural gas port injection and diesel pilot injection) engine using 0-D SRM and 3D CFD approach, Fuel 210: 900-913. https://doi.org/10.1016/j.fuel.2017.09.021

Merker, G.; Schwarz, C.; Stiesch, G.; Otto, F. 2006. Simulating Combustion: Simulation of Combustion and Pollutant Formation for Engine-Development. Springer. $402 \mathrm{p}$. https://doi.org/10.1007/3-540-30626-9

Mustafi, N. N.; Raine, R. R.; Verhelst, S. 2013. Combustion and emissions characteristics of a dual fuel engine operated on alternative gaseous fuels, Fuel 109: 669-678. https://doi.org/10.1016/j.fuel.2013.03.007

Nithyanandan, K.; Lin, Y.; Donahue, R.; Meng, X.; Zhang, J.; Lee, C.-F. F. 2016. Characterization of soot from diesel-CNG dual-fuel combustion in a CI engine, Fuel 184: 145-152. https://doi.org/10.1016/j.fuel.2016.06.028

Papagiannakis, R. G.; Rakopoulos, C. D.; Hountalas, D. T.; Rakopoulos, D. C. 2010. Emission characteristics of high speed, dual fuel, compression ignition engine operating in a wide range of natural gas/diesel fuel proportions, Fuel 89(7): 13971406. https://doi.org/10.1016/j.fuel.2009.11.001
Rapalis, P.; Lebedeva, G.; Gudaitytè, I. 2013. Comparative analysis of diesel engine mathematical modelling packages for practical use on transport diesel engine operating on biodiesel, in Transbaltica 2013: the 8th International Conference: Selected Papers, 9-10 May 2013, Vilnius, Lithuania, 173-178. https://doi.org/10.3846/transbaltica2013.038

Rimkus, A.; Berioza, M.; Melaika, M.; Juknelevičius, R.; Bogdanovičius, Z. 2016. Improvement of the compression-ignition engine indicators using dual fuel (diesel and liquefied petroleum gas), Procedia Engineering 134: 30-39. https://doi.org/10.1016/j.proeng.2016.01.035

Rimkus, A.; Melaika, M.; Matijošius, J. 2017. Efficient and ecological indicators of CI engine fuelled with different diesel and LPG mixtures, Procedia Engineering 187: 504-512. https://doi.org/10.1016/j.proeng.2017.04.407

Thomson, H.; Corbett, J. J.; Winebrake, J. J. 2015. Natural gas as a marine fuel, Energy Policy 87: 153-167. https://doi.org/10.1016/j.enpol.2015.08.027

Wang, T.; Zhang, X.; Zhang, J.; Hou, X. 2017. Numerical analysis of the influence of the fuel injection timing and ignition position in a direct-injection natural gas engine, Energy Conversion and Management 149: 748-759.

https://doi.org/10.1016/j.enconman.2017.03.004

Yousefi, A.; Birouk, M.; Guo, H. 2017. An experimental and numerical study of the effect of diesel injection timing on natural gas/diesel dual-fuel combustion at low load, Fuel 203: 642-657. https://doi.org/10.1016/j.fuel.2017.05.009

Yousefi, A.; Birouk, M.; Lawler, B.; Gharehghani, A. 2015. Performance and emissions of a dual-fuel pilot diesel ignition engine operating on various premixed fuels, Energy Conversion and Management 106: 322-336. https://doi.org/10.1016/j.enconman.2015.09.056

Zhang, C.; Zhou, A.; Shen, Y.; Li, Y.; Shi, Q. 2017. Effects of combustion duration characteristic on the brake thermal efficiency and $\mathrm{NO}_{\mathrm{x}}$ emission of a turbo diesel engine fueled with diesel-LNG dual-fuel, Applied Thermal Engineering 127: 312318. https://doi.org/10.1016/j.applthermaleng.2017.08.034 